\title{
ORGANIZAÇÃO RELIGIOSA: PESSOA JURÍDICAAMORFA NO CÓDIGO CIVIL DE 2002
}

\author{
SUYENE MONTEIRO DA ROCHA
}




\section{ORGANIZAÇÃO RELIGIOSA: PESSOA JURÍDICA AMORFA NO CÓDIGO CIVIL DE 2002}

Suyene Monteiro da Rocha'

\section{RESUMO}

A organização religiosa sempre foi considerada associação em sua essência, por se caracterizar pela união de pessoas sem fins econômicos. A organização religiosa tem como finalidade ou função a divulgação de determinado preceito religioso, por um grupo de pessoas, preenchendo os requisitos legais de associação. Entretanto, esta era sua naturezajurídica atédezembro de2003, quando o Código Civil em seu art. 44 sofre uma al teração, a inserção das organizações religiosas nas espécies de pessoas jurídicas de direito privado. Assim o presente trabal ho pretendeu real izar uma análise crítica jurídica da natureza das organizações religiosas com a nova feição inserida pelo legislador no referido códex, na busca de compreender a existência e aplicabilidade da personalidade juń́dica associação e organização religiosa na estrutura civilista.

Palavras-chave Organização religiosa. Código civil. Associação. Naturezajuńdica.

\section{ABSTRACT}

The organization has al ways been consi dered religious association in essence, because it is characterized by the union of people without economic purposes. The religious organization has as its purpose or function the dissemination of religious precept given by a group of people, fulfilling the legal requirements of the association. However, this was their legal status until December 2003 when the civil code in its art. 44 is altered, the inclusion of religious organizations in

$1 \quad$ Bacharel em Direito pela Universidade do Tocantins; Pós-Graduação em Direito Penal eDireito Processual Penal pelaUnivale; Mestreem CiênciasAmbientais pelaUniversidade Federal do Tocantins. Docente nas disciplinas de Direito Civil, Direito Empresarial e Direito Ambiental. Membro do Núcleo de Estudos Contemporâneos da Universidade Federal do Tocantins. Exerce a advocacia desde 2001. Docente na Universidade Federal do Tocantins e no Centro Universitário Luterano de Pal mas. E-mail: suyenerocha@hotmail.com 
the kinds of legal entities under private law, so this study sought to conduct a legal review of the nature of religious organizations with a new face entered thelegislaturein that codex, in sedking to understand the existence and applicability of legal personality association and religious organization in the civil structure.

Keywords Religious organization. The Civil Code. Association. Legal.

\section{IINTRODUÇÃO}

O homeméumser eminentementesocial , os historiadores em suas narrativas nos mostram a necessidade de estar em agrupamentos, seja como intuito deseal iar para caçar ou mesmo se proteger das adversidades do ambiente. Aliar-se a outro ou outros, na formação de uma vida em comum ou objetivos de vida, é válvula motriz para o agregar. Na modernidade, a vida em conjunto ou a busca de se viver em grupo tem como escopo al cançar objetivos sejam de ser aceito socialmente, estruturar um núcleo familiar ou mesmo alcançar expoente profissional, essas são metas básicas que qual quer indi víduo mediano al meja.

Mas para alcançar alguns desses objetivos, como por exemplo, o de consolidação na esfera comercial, indivíduos deslocam de si o direito e formam um ente diverso, a pessoa junídica. Esse passa a ser o que movimenta ou dá forma aos anseios do grupo que pretende se inserir no mercado.

Para Gonçal ves (2007, p. 182), a razão de ser da pessoa jurídica está na necessidade ou conveniência de os indivíduos uni rem esforços e utilizarem recursos coletivos para real ização 
de objetivos comuns, que transcendem as possibilidades individuais.

O presente trabalho tem como escopo refletir acerca das pessoas jurídicas de direito privado, mais especificamente a inserção, em 2003, de uma nova modal idade: a organização religiosa. O objetivo é trazer questionamentos a essa natureza jurídica, tão excêntrica, criada pelo legislador.

\section{DA ORIGEM DA PESSOA J URÍDICA}

Buscando a origem da Pessoa Jurídica no ordenamento legal, Coelho (2009, p. 231) nos informa que o "alicerce das pessoas juńdicas encontra-se na Idade Média, em noções destinadas a atender as necessidades de organização da I greja Católica e preservação do seu patrimônio." O intuito era poder traçar uma di stinção clara e precisa entre o patrimônio da igreja ea dos seus membros, fazendo com que a igreja não tivesse de partilhar suas posses com os sucessores de padres ou bispos.

Já na Revolução Comercial, as companhias que desenvol viam a exploração e col onização do novo mundo eram consi deradas enti dades autônomas em re lação a seus fundadores einvestidores.

Mas não se pode afirmar que o conceito de pessoa jurídica se formou assim, de forma imediata. Não se tem base de consolidação no direito romano (WALD, 2009, p. 185). Há todo um percurso transcorrido de estruturas, pensamentos e teorias para só na segunda metade do século XIX ser um 
parâmetro conceitual formado, que se deu a partir da reflexão de doutrinadores al emães (COELHO, 2009).

Para Coelho (ibidem, p. 233)

o instituto da pessoa jurídica é uma técnica de separação patrimonial. Os membros dela não são os titulares dos direitos e á obrigações imputados à pessoa juńdica. Tais direitos e obrigações formam um patrimônio distinto do correspondente aos di reitos e obrigações imputados a cada membro da pessoa jurídica.

Já Gagliano e Pampolha Filho (2008, p. 182) definem pessoa jurídica como sendo o grupo humano, criado na forma da lei, e dotado de personal idadejurídica própria, para a real ização de fins comuns.

Diniz (2007, p. 229), ao traçar parâmetro para a pessoa jurídica, a define como sendo a unidade de pessoas naturais ou de patrimônio, que visa à consecução de certos fins, reconhecida pela ordem jurídica como sujeito de di reitos e obrigações.

Assim, observarse haver congruência de elementos na composição do conceito pelos doutrinadores, há de se ter um conjunto de indivíduos que buscam um objeto em comum. Adiante será feita uma reflexão mais apurada desses elementos.

\section{DO CÓDIGO CIVIL DE 1916PARA O CÓDIGO DE 2002}

Para entender a pessoa juńdica emsua estrutura épreciso entender a construção do Código Civil. Desde a Constituição 
Brasileira de 1824 previam-sedois códigos, o Civil eo Criminal, mas apenas o segundo foi concretizado. A pós a independência do Brasil, permaneceu em vigor a legislação portuguesa, que correspondia às Ordenações Filipinas.

Houve, pelo menos, quatro tentativas de elaboração do Código Civil: a primeira em 1845, do Barão de Penedo, que apresentou seu Da Revisão Geral e Codificação das Leis Civis e do Processo no Brazil; em 1864, o Esboço inacabado deA ugusto Texxeira de Freitas, que não chegou a ser aprovado, mas serviu de base para os códigos civis do Uruguai e da Argentina; em 1881, o projeto Felício dos Santos, e, em 1890, o projeto Coel ho Rodrigues (AGUIAR, 2006).

Todavia, sob a presidênciadeCamposSal eseaconvitede seu amigo de congregação da Facul dade de Direito do Recife, o Ministro daJ ustiça Epitácio Pessoa, Clóvis Beviláqua apresenta, após seis meses de trabal ho, seu projeto de Código Civil, em 1901. Duramente criticado por Rui Barbosa e por vários juristas da época, como Inglês de Sousa e Torres Neto. O trabal ho de Beviláqua foi fortemente influenciado pelo Código Civil alemão (BGB) e sofreu várias al terações atésua aprovação, em 1916.

Assim, tem-sequeo projeto do Código Civil de 1916 foi de autoria de Clóvis Beviláqua, que entrou em vigor em 1o de janeiro de 1917. A sociedade que vigia à época era patriarcal e rural (MARTINS, 2009). Até a obtenção da aprovação do texto final foram quinze anos de discussão.

Para Tepedino (2009), o Código Civil de 1916 refletia o pensamento dominante das elites europeias do século XIX, 
marcadamente individualista e liberal.

Um código que teve sua redação inicial em 1889 eentrou em vigor em 1917 com as al terações sociais vividas no Brasil, revolução industrial, inserção da mulher no mercado e ditadura, fez comque o referido códex iniciasse o seu declínio normativo. Declínio no sentido, de não atender mais aos anseios sociais, principal mente no tocante à família.

A promulgação da Carta Constitucional de 1988 foi o gol pe derradeiro para o direito privado. A igual dade de direitos entre homens e mulheres, as garantias constitucionais e os direitos da família fizeram com que os tribunais começassem a prolatar sentenças com base nos princípios constitucionais, deixando delado cadavez maisas interfaces como Código Civil, tendo em vista que seus di spositivos não coadunavam mais com os preceitos vigentes na sociedade brasileira. O código civil de 1916 vigorou quase 100 anos.

O que a priori poderia ser um espanto, falar de direito constitucional edireito civil juntos, dando embasamento jurídico a fatos, com certeza, hoje, não é fato tão assombroso. “De todos os ramos jurídicos são o di reito civil eo direito constitucional os que mais dizem respeito ao cotidiano de cada pessoa humana e da cada cidadão." (LÔBO, 2009, p. 315).

Corroborando com a assertiva, Viegas (2009, p. 159), ao citar o pensamento de Heildel berg, entende que

necessita do diálogo das fontes no direito brasileiro mediante uma coordenação útil e flexível das normas em conflito, com a finalidade de restabelecer uma coerência, 
ou seja, uma mudança de paradigma Devendo seevoluir da simples retirada de uma noma do ordenamento jurídico, porque aparentemente pode conflitar com outra, para se buscar uma possível comunicação normativa destinada a convivência das normas no ordenamento, através da anál ise das convergencias e divergências de cada uma delas.

\section{Lôbo (2008, p. 23) muito bem coloca que}

cada interpretação é um microcosmo da imensa tarefa de real ização de uma sociedade livre, justa e solidária. O Código Civil cumprirá sua vocação de pacificação social se for efetivamente iluminado pelos valores maiores que foram projetados nas nomas constitucionais, notadamente nos princípios.

Depois depequenorecorteatítul odemai or esclarecimento do diálogo que deve haver entre os sistemas normativos, há um percurso longo e penoso percorrido pelo projeto de lej que visava atual izar o código civil. Foram diversas as tentativas de elaboração de novos códigos, como o Anteprojeto de Código das Obrigações de Orozimbo Nonato, Filadelfo Azevedo e Hannemann Guimarães da década de 1940, e o de Caio Mário da Silva Pereira, de 1963. Mas foi uma comissão encabeçada por Miguel Reale, formada em 1969, durante a ditadura, que obteve mai or êxito. Então, publica em 1973 o seu Anteprojeto de Código Civil, fortemente influenciado pelo Código Civil italiano, trabal ho este encaminhado pelo Governo ao Congresso Nacional, ondesetransforma no Projeto de Lei n.ㅇ 634, de 1975. Depois de quase três décadas, sob a presidência de Fernando 
Henrique Cardoso, o Congresso retoma o seu exame e o aprova, em2002.

A Lei no 10.406, de 10 de janeiro de 2002, já nasce sob o manto da crítica. Estudiosos afirmam que o código já vinha desatualizado diante da modernidade vivida pela sociedade brasileira, citam como exemplo a ausência de uma abordagem normativa acerca das questões digitais, o não disciplinar das questões de biodireito e a inserção do direito empresarial como livro do Código Civil.

Mas, sob bons ou maus olhares em 11 dejaneiro de 2003, entrou em vigor o Novo Código Civil Brasileiro. Modificações profundas foram introduzidas pel o novo Códex, princi pal mente na parte geral, a inserção de um capítulo próprio para o direito de Personal idade foi, para nós, a alteração mais expressiva para os interesses da pessoa natural, em que pesem afirmações de que tudo o que está previsto neste capítulo já estava de certa forma pacificado pelos tribunais. Segundo Charles Taylor (1999, p. 118), os direitos da personalidade pressupõem três requisitos básicos: autonomia de vontade, alteridade e dignidade. A autonomia da vontade é o pressuposto único em que cada indivíduo tem autonomia moral de que deve gozar toda pessoa humana. A alteridade representa o reconhecimento do ser humano como sendo único, tornando-o diferente de seus semelhantes. A dignidade é uma característica cumulativa, ou até mesmo derivada, porque existe quando o ser humano for autônomo em suas vontades efor reconhecida al teri dade perante a sociedade em que convive. 
Mas que pertinência tem o direito de personal dade da pessoa natural em relação ao assunto hora discutido? Toda pertinência e congruência, quando o assunto em questão é a vontade. Isso porque o livro I, título I, capítulo II, é um marco para a pessoa natural. O Título II do mesmo livro vem fazendo uma mudança expressiva no que concerne às pessoas jurídicas. E onde entra a vontade? Essa é a propul são para que haja uma pessoajuridica de di reito privado sem vontade humana criadora, não há esse entejuridico.

São três as bases para que se possa ter uma pessoa juridica: vontade humana criadora, liciedade da finalidade e observância aos preceitos legais. A vontade humana é o gênese para que haja uma pessoa juridica, o indivíduo tem de querer juntar-se a outro com uma finalidade definida e em consonância com o ordenamento jurídico.

\section{OS CAMINHOS DITADOS PARAASASSOCIAÇÕES E ASORGANIZAÇÕESRELIGIOSAS NO CÓDIGO CIVIL DE 2002}

Embora mantida a classificação geral das pessoas jurídicas, dividindo-as em pessoas jurídicas de direito público e pessoas jurídicas de direito privado, a classificação específica destas últimas sofreu alteração em relação à classificação que Ihes era dada pelo Código Civil de 1916. Não mais existe a classificação das sociedades civis, com ou sem fins lucrativos, e sociedades comercias. A estrutura das pessoas jurídicas de 
direito privado, agora, obedece, num primeiro momento, a três tipos: as associações, as sociedades eas fundações.

O termo "sem fins lucrativos" é alterado para "sem fins econômicos", reflexo de uma ponderação simplista. O termo lucro nos traz à mente a venda de um objeto no qual retiramos seu custo de produção e ainda um extra (o lucro) por têlo produzido. Já o fim econômico nos remete à comercialização do produto ou serviço por si, sem o plus, o lucro.

O foco deste trabal ho são as pessoas jurídicas de direito privado, que está disciplinada quanto a sua classificação no art. 44:

Art 44. São pessoas jurídicas de direito privado:

I - as associações;

II - as sociedades;

III - as fundações.

O conceito de associação está disposto no artigo 53, "constituem-se as associações pela união de pessoas que se organizem para fins não econômicos". Esse conceito incorporou o pensamento da doutrina, que definia a associação como sendo a sociedade civil sem fins lucrativos, à época em que vigorava o Código Civil de 1916, que, aliás, não fazia distinção entre sociedade e associação.

Pereira (2005, p. 350) conceitua associação aquela "que se propõe a realizar atividades não destinadas a proporcionar interesse econômico aos associados". A associação propõe-se a outras finalidades que não as econômicas ou, quando visa 
vantagens materiais, elas não se destinam precipuamente aos seus associados. Colima objetivos al truístas, morais, religiosos, de interesse geral, em benefício de toda a comunidade ou de parte dela, e não dos sócios particularmente.

Diniz (2007) traça um rol exemplificativo bem amplo de espécies de associações, podem elas ser: pias, beneficentes ou filantrópicas; de assistência social; de utilidade pública; organizações religiosas; espiritual istas ou espíritas; secretas; estudantis; formadas para manutenção de escolas livres ou de extensão cultural; culturais; desportivas; entre outras.

Um aspecto importante a se observar é o de que em função das alterações real izadas pelo legislador na estrutura e organização das associações, a uma necessidade de adaptação dessas pessoas junídicas, aos termos da nova lei civil. $\mathrm{O}$ art. 2.031 do Código Civil de 2002 prevê o prazo de umano para as associações, constituídas na forma das leis anteriores, poderem se adaptar às disposições do novo Código Civil.

O mais interessante que se pode observar com a nova redação legal é que a assembleia geral passa a ter uma força maior na direção das associações.

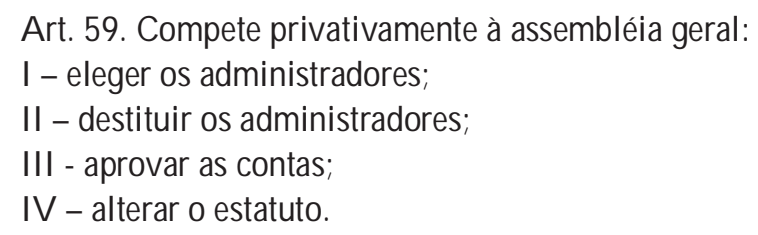


Parágrafo único. Para as deliberações a que se referem os incisos II e IV é exigido o voto concorde de dois terços dos presentes à assembleia especialmente convocada para esse fim, não podendo ela deliberar, em primeira convocação, sem a mai oria absoluta dos associados, ou commenos de um terço nas convocações seguintes.

A redação como foi dada, em termos práticos, significa uma alteração estatutária significativa, num paralelo com as disposições normativas do Código Civil de 1916. Assim, necessário se fez instituir uma força tarefa nas entidades religiosas para que pudessem se adequar às novas exigências legais. Reorganizar umestatuto não éuma situação fácil, quando se tem um conjunto significativo de pessoas que, na maioria das vezes, não possuem um universo jurídico relevanteque as façam entender as "necessidades" legais.

A Assembleia Geral temum poder de decisão muito mais expressivo do que continha no Código Civil de 1916. Passa, a partir de então, a eleger os administradores, aprovar contas e alterar o estatuto. As atribuições de destituição da direção administrativa e alteração estatutária requerem convocação específica para tal fim, exige-se ainda, que, para o início da reunião, esteja presente a maioria absoluta das associações para a abertura da primeira convocação, e as demais convocações devem contar com 1/3 dos associados presentes, para que as deli berações da pauta tenham validade, o quórum de associados que anuam com as alterações deve ser de $2 / 3$ dos presentes. A assembleia geral deixa de ser uma parte e passa a ter força na 
organização da associação.

O prazo para promover todas as alterações estatutárias é de um ano, ou seja, no início de 2003 todas as adequações deveriam estar prontas, entretanto, em função do pequeno número de organizações que conseguiram realizálas, o Congresso Nacional prorroga o prazo por mais umano.

Enquanto as entidades religiosas se ocupavam em organizar o seu estatuto à luz das novas disposi ções civilistas, o legislador, em22 de dezembro de 2003, publica a Lé № 10.825 que altera o texto do art. 44, e assim começa uma celeuma jurídica instaurada, pois o Legislador dá inicio a uma sequência desastrosa de modificações na redação dos artigos que têm como fim disciplinar as questões atinentes à pessoa jurídica de direito privado. A primeira delas éa redação do artigo supracitado, que passa a ter a seguinte redação:

Art 44. São pessoas juŕdicas de direito privado:

I - as associações;

II - as sociedades;

III - as fundações.

IV - as organizações religiosas; (Indúdo pela Le no 10.825, de22.122003)

V - os partidos políticos. (Incluído pela Lei no 10.825, de 22122003)

$\S 1$ o São livres a criação, a organização, a estruturação interna e o funcionamento das organizações religiosas, sendo vedado ao poder público negar-Ihes reconhecimento ou registro dos atos constitutivos e necessários ao seu funcionamento. (Induído pela Lei no 10.825, de 22122003)

$\S 22^{\circ}$ As disposições concementes às associações aplicam 
se subsidiariamente às sociedades que são objeto do Livro II da Parte Especial deste Código. (Inclú́do pela Lei no 10.825, de22.12.2003)

$\S$ 3Os partidos políticos serão organizados e funcionarão conforme o disposto em lei específica. (Induído pela Le no 10.825, de 22.12.2003) - (grifo nosso)

Observe-se que a nova redação do artigo 44 altera substancial mente a estrutura a ser seguida pelas organizações religiosas. Se até então eram consideradas associações quanto a sua natureza juńdica, passama partir de então ter feição própria - serem organizações religiosas. Possuem agora autonomia na sua natureza jurídica, ou seja, não são mais consideradas associações.

Para quetal fato seja possível, ao seanal isar sua essência, o intérprete deverá atribuir a ela uma ou outra espécie, ou é associação ou é organização religiosa. Mas a questão é mais crucial, se voltar ao citado anteriormente ao tema objeto finalidade da pessoa jurídica, ver-se-á que os doutrinadores são uníssonos em se referir às organizações religiosas como uma modalidade de associação, uma vez que ao se questionar juridicamente a sua estrutura constitutiva obter-seá como resposta "união de pessoas sem fins econômicos".

Corroborando com tal assertiva, Szazi (2003, p. 27) define associação como "pessoa jurídica criada a partir de uma união de ideias e esforços de pessoas em torno de um propósito que não tenha finalidade lucrativa." Observem uma organização religiosa e vejam se ela não se enquadra perfeitamente na 
definição acima? O fato de ter como propósito um preceito religioso não a descaracteriza de ser uma associação. Não há como deixar de reconhecer que são verdadeiras associações, ai nda que com características especiais.

Gagliano (2008, p. 206) estabelece que o legislador cometeu um erro conceitual,

pois tanto as organizações religiosas quanto os partidos políticos se enquadram perfeitamente no conceito jurídico de associação, bem como as cinco alíneas não elencam todas as modalidades de pessoas jurídicas de direito privado, tornando-se tal rol meramente exemplificativo.

Ao conceituar organizações religiosas, Gagliano (I bdem, p. 223) as define como sendo "todas as entidades de direito privado formada pela união de indivíduos com o propósito de culto e determinada força ou forças sobrenaturais, por meio de doutrina e ritual próprios, envolvendo, em geral, preceitos éticos".

Para que se possa entender a norma, sua amplitude, aplicabilidade e eficácia, há de se interpretar o texto legal. Grau (2008, p. 283) define interpretação como sendo uma relação entre duas expressões. "A primeira expressão que porta uma significação, que é o objeto da interpretação. E uma segunda, que nós chamamos de interpretação e cumpre a função do interpretante". Continua Grau (ibdem, p. 284), “o que quer dizer é que a interpretação é mais que um exercício de simples compreensão ou conhecimento do que está escrito nas leis. A 
norma, então, passa a ser uma construção do intérprete.

E buscando realizar um processo da função da norma, procurou-se o texto da Lei no 9.790/99, mais conhecida como a Lei das OSCIP - Organização da Sociedade Civil de interesse público. Percebe-se que em seu art. 2으, III, o legislador exclui da possibilidade obtenção da declaração de interesse público as "instituições religiosas ou voltadas para a disseminação de credos, cultos, práticas evisões devocionai s econfessionais." A justificativa para tal ato se dá na função e finalidade do Estado versus os interesses das organizações religi osas, ou seja, o Estado tem por interesse sal vaguardar o bem-estar do homem, enquanto que, para os entes religiosos, o homem é o caminho, meio pelo qual se salva a al ma, seja para a vida eterna, para o jul gamento final, para o encontro com a Divindade Superior.

Nesse diapasão, Perlingiere (1997, p. 28), ao tergiversar acerca das definições legislativas e principalmente sobre o valor dessas definições, afirma que

as definições, contudo, são, não somente oportunas, mas necessárias, e não só para exprimir, em conformidade com a lógica aristotélica, o real conteúdo que a palavra definida encerra em si, mas para indicar simplesmente o conjunto de regras que estabel ecemo uso da palavra correspondente.

Complementa Perlingiere (ibdem, p.30) [...], o val or é unitário, os seus aspectos são múltiplos: políticos, sociológicos, filosóficos, jurídicos. É necessário ter consciência da unidade da noção, [... ] o val or se torna o resul tado, não de umúnico critério, 
mas de um critério sincrético, devido a tantos aspectos, todos eles concorrentes. Há de se verificar a função da norma.

Ao inserir no art. 44 a natureza jurídica da organização religiosa, a definição, o valor e a função da norma não ficam claros. O legislador acaba por criar uma anomalia jurídica, que passa a ser considerada pelos doutrinadores como simples exemplificação de um rol não taxativo.

Num caso hi potético, tendo o Governo Federal o intuito de excluir a concorrência das organizações religiosas de um contrato ou concorrência pública, bastaria que o texto do documento apresentasse a definição dada às entidades religiosas pela Lei de OSCIP, sendo discipienda a inserção de uma nova figura jurídica no art. 44. Haveria, assim, uma congruência de pensamento quanto à definição e o valor da norma.

No que tange ao parágrafo primeiro do art. 44 é mera repetição do texto constitucional art. 19, I.

Art 19. É vedado à União, aos Estados, ao Distrito Federal eaos Municípios:

I - estabelecer cultos religiosos ou igrejas, subvencioná los, embaraçar-Ihes o funcionamento ou manter com eles ou seus representantes rel ações de dependência ou al iança, ressalvada, na forma da lei, a colaboração de interesse público;

II - recusar fé aos documentos públicos;

III - criar distinções entre brasileiros ou preferências entre si.

Tepedino e Lewicki (apud GAGLIANO, ibidem, p. 224) discorre acerca deste assunto, afirmando que "a liberdade de 
funcionamento das organizações religiosas não afasta o controle de legalidade e legitimidade constitucional de seu registro, nem a possibilidade de reexame, pelo judiciário, da compatibilidade de seus atos com a lei e com seus estatutos."

Como o objeto de estudo são as organizações religiosas, os incisos seguintes do artigo 44 não serão analisados nesse artigo.

A pós a tormentajurídica criada em2003, o legisl ador em 2005, edita a Lé ํo 11.127/2005, que revoga integralmente o texto do artigo 59 el he dá nova redação.

Art 59. Compete privativamente à assembléia geral:

I - destituir os administradores;

II - alterar o estatuto.

Parágrafo único. Para as deliberações a que se referem os incisos I ell desteartigoéexigido del iberação da assembléia especialmente convocada para esse fim, cujo quorum será o estabelecido no estatuto, bem como os critérios de eleição dos administradores

A al teração trazida pelo Código Civil em 2002 requereu esforço dos di rigentes de associações para real izar as mudanças em tempo, entretanto, quando se imagina estar em consonância comas determinaçõeslegais novas mudanças surgem O Códi go Civil determinou o prazo de um ano para a al teração estatutária, o prazo final era para 2004. Teoricamente, as associações que estivessem cumprindo o prazo legal, em 2005, já teriam promovido as mudanças, e teriam, com a nova disposição, de al terar novamente seu estatuto. Nesse caso, as associações que 
não tivessem cumprido o prazo legal teriam sido beneficiadas com a inconstância do legisl ador.

\section{CONSIDERAÇÕES FINAIS}

O legislador, ao tentar reestruturar ou mesmo inovar as disposições legais pertinentes à pessoa juńdica de direito privado, acabou criando uma confusão, visto ter, de2002 a 2005, promovido al terações desconexas nos artigos que disciplinama matéria.

Ao criar uma nova natureza jurídica, trouxe ao intérprete da norma uma dificuldade de contextualização, pois acabou tendo de enquadrar a entidade religiosa em dois tipos: a associação e a organização religiosa. O que, a priori, é uma situação que se configura em pleonasmo, pois passa a ser considerada duplamente, união de pessoas sem fins econômicos. A conotação divergente fica a cargo da finalidade, ter por escopo amparar indivíduos socialmente menos favorecidos, ensinar práticas esportivas, propiciar lazer e cultura, ou mesmo pregar ensinamentos religiosos. A finalidade é a modalidade de atuação que os indivíduos que desejam criar a associação escol hem para atuar.

Que a pessoa junídica de direito privado é dotada de capacidade e personalidade jurídica é fato inconteste, na atual idade Que possui um arcabouço de direitos e obrigações também não está em discussão, mas sim o motivo que levou - legislador a criar uma estrutura normativa sem bases de 
sustentação.

Há de se ponderar acerca da função nomativa, mais especificamente a função ao se criar nova natureza jurídica, e no caso emanál isenão sevisl umbra respostaque possua ser al icerce capaz de suportar as paredes firmes na qual está assentada a essência da pessoa jurídica de di reito privado.

Assim, ao gerar a pessoa jurídica organização religiosa, - legislador pecou pela ausência de técnica legislativa, não observou a função normativa. Criando em nosso ordenamento uma figura anômala, carente de essência. Um ser sem vida tangível no contexto social. Pois as entidades religiosas serão, pelo menos até que uma estrutura mais contundente surja, consideradas uma junção de pessoas sem fins econômicos, e, assim sendo, definidas como associações. 


\section{REFERÊNCIAS BIBLIOGRÁFICAS}

AGUIAR, Antonio Chrysippo de. Direito Civil: Coelho R odrigues e a ordem de silêncio. 1 ed. Teresina, 2006.

BRASI L, Código C ivil Brasileiro. Lei 10.406, de 10 dejaneiro de2002. Disponível em:<http://www.planalto.gov.br/ccivil_03/ LEIS/2002/L10406.htm>Acesso em 12. Jan. 2010.

- Constituição da República Federativa do Brasil 1988. Disponível em:< http://www.planalto.gov.br/ccivil_03/ Constituicao/Constituiçao.htm>Acesso em 15. J an. 2010.

, OSCIP. Organização da sociedade civil de interesse público: a lei 9.790/99. Brasilia: Comuni dade Solidária, 2000.

COELHO, Fábio Ulhoa. C urso de Direito Civil - parte geral vol 1. 3 ed. Revis - São Paulo: Saraiva, 2009.

DINIZ, Maria Helena. C urso de Direito Civil Brasileiro vol 1. 24 ed. Revista eatual izada. São Paul o: Saraiva, 2007.

GAGLIANO, Pablo Stolze; PAMPLONA FILHO, Rodolfo. Novo C urso de Direito Civil vol 1. 10 ed. Ver e atual. São Paulo: Saraiva, 2008.

GONÇALVES, Carlos Roberto. Direito C ivil B rasileiro. Parte 
geral vol 1. 5 ed. Revisto eatual izado. São Paul o: Saraiva, 2007.

GRAU, Eros. Técnical egisl ativa ehermenêuticacontemporânea. In: Direito Civil contemporâneo: novos problemas à luz da legalidade constitucional. Gustavo Tepedino (org.) São Paulo: Attas, 2008, p. 282-288.

MARTINS, Sergio Pinto. Instituições de Direito Público e Privado. 9 ed. São Paulo: Atlas, 2009.

LÔBO, Paulo Luiz Netto. A constitucionalização do di reito civil brasileiro. In: Direito C ivil contemporâneo: novos problemas à luz da legal idade constitucional. Gustavo Tepedino (org.) São Paulo: Attas, 2008, p. 18-28.

, Direito Civil constitucional na contemporaneidade Brasileira. In: Direito Civil Contemporâneo. Frederico Viegas (org.) 1 ed. Braślia: Obcursos Editora, 2009, p. 313-336.

PEREIRA, Caio Mario da Silva. Instituições de Direito Civil. Vol 1. 21 ed. Rio deJ aneiro: Forense, 2005.

PERLINGIERE, Pietro. Perfis do Direito Civil - Introdução ao Direito Civil Constitucional. 3 ed. Rev. e ampl. Rio de Janeiro: Renova, 1997.

SZAZI, Eduardo. Terceiro Setor: regulação no Brasil. 3 ed. São 
Paulo: Peirópolis, 2003.

TEPEDINO, Gustavo. Marchas e contramarchas da Constitucionalização do Direito Civil: a interpretação do direito privado à luz da Constituição da República. In: Direito Civil Contemporâneo . Frederico Viegas (org.) 1 ed. Brasília: Obcursos Editora, 2009, 203- 212.

VIEGAS, Frederico. 0 delineamento da propriedade imobiliária na pós modernidade. In: Direito Civil Contemporâneo . Frederico Viegas (org.)1 ed. Brasília: Obcursos Editora, 2009, 151-190.

WALD, Arnoldo. Direito C ivil: introdução e parte geral vol 1. 11 ed. Reformada. São Paulo: Saraiva, 2009. 